\title{
Hydrological and Temperature change in Arctic Siberia during the Intensification of Northern Hemisphere Glaciation Supplementary Text
}

\author{
Benjamin A. Keislinga,*, Isla S. Castañeda ${ }^{a}$, Julie Brigham-Grette ${ }^{a}$ \\ ${ }^{a}$ Department of Geosciences, University of Massachusetts Amherst, 233 Morrill Science Center, 611 \\ North Pleasant St., Amherst, MA 01002, USA
}

\section{Observations of Facies Change}

Earlier studies of the Lake El'gygytgyn drill core noted distinct facies changes accompanied some glacial-interglacial climate transitions (Gebhardt et al., 2013; BrighamGrette et al., 2013). The facies of interest are glacial facies A, thought to represent year-round lake-ice cover, and super-interglacial facies C, thought to represent extreme warmth and high productivity.

Super-interglacial facies C occurs during MIS G9, G7, G3, and G1. We reconstruct distinct warm periods during MIS G9, G7, G3, and, within age-model error, G1. However, we also reconstruct high temperatures during MIS 100, 99, 97/96, and 95, which are not accompanied by physical facies change. Facies $\mathrm{C}$ does occur later in the Pleistocene, and continued application of the MBT/CBT temperature proxy at Lake $\mathrm{E}$ will refine our understanding of what causes this super interglacial facies. If MBT/CBT is accurately capturing the variability in temperature on glacial-interglacial timescales, there must be another important parameter (i.e. nutrient availability) that acts with temperature to produce facies $\mathrm{C}$ during some intervals.

Glacial facies A appears for the first time during MIS 104, and appears again during MIS 98 and 96. Although previous work has suggested a threshold of year-round lake-ice cover for producing facies $\mathrm{A}$, which is expected if MAAT drops $4{ }^{\circ} \mathrm{C}$ below present values, the brGDGT and $\delta \mathrm{D}_{\text {wax }}$ reconstructions do not indicate that this threshold existed in the Late Pliocene (Nolan and Brigham-Grette, 2006; Brigham-Grette et al., 2013). During MIS 104, we reconstruct a cooling from $\sim 14^{\circ} \mathrm{C}$ to $\sim 10^{\circ} \mathrm{C}$, but lower temperatures $\left(6-7^{\circ} \mathrm{C}\right.$, MIS G10, G6) and larger temperature changes $\left(11^{\circ} \mathrm{C}\right.$ to $6^{\circ} \mathrm{C}$, MIS G7/G6) occur prior to this interval. It is interesting that this facies first appears during MIS 104, a period during which many climatic changes in the northern hemisphere occurred. Notably, this is not directly supported by the reconstructions we present here. This may be an indication of the spatial scale our reconstructions, with facies change representing a more regional, or even hemispheric, signal. Previous workers have found that sediment color in the

\footnotetext{
* Corresponding Author

Email address: bkeisling@geo.umass.edu (Benjamin A. Keisling)
} 
Pleistocene is driven at least partially by changes in precipitation (Wei et al., 2014), but we expect that to be captured by the $\delta \mathrm{D}_{\text {wax }}$ record we present. Thus, it is not clear why the first appearance of facies $\mathrm{A}$ is not accompanied by large changes in the MBT/CBT and $\delta \mathrm{D}_{\text {wax }}$ records we present.

MIS 98 and 96 are both distinct cold periods in the MBT/CBT record. Low $\delta \mathrm{D}_{\text {wax }}$ values occur during MIS 98, but relatively high $\delta \mathrm{D}_{\text {wax }}$ values occur during MIS 96. Higher resolution pollen records are needed to make a confident assessment of temperature change from that proxy during this interval (Figure 3b,d). However, if temperature is the dominant control on facies $\mathrm{A}$, it is perplexing that the facies does not occur during MIS 102, which is a very cold glacial period in the MBT/CBT reconstruction and contains very low $\delta \mathrm{D}_{\text {wax }}$ values. Similar to facies $\mathrm{C}$, our reconstructions suggest that factors beyond temperature exert at least a secondary control on the deposition of glacial facies A.

\section{Conversion from $\delta \mathrm{D}_{w a x}$ to $\delta \mathrm{D}_{P}$}

The deuterium to hydrogen ratio $(\delta \mathrm{D})$ of plant leaf waxes reflects the $\delta \mathrm{D}$ of precipitation $\left(\delta \mathrm{D}_{P}\right)$, which depends on the extent of Rayleigh distillation of a precipitating water mass (Dansgaard, 1964). At high latitudes, modern $\delta \mathrm{D}_{P}$ is strongly correlated with temperature (Pautler et al., 2014), and can thus provide a complementary measure to brGDGT-based temperature reconstructions. Work on $n$-alkanoic acids from plants in the Lake El'gygytgyn catchment and local water samples found a biosynthetic fractionation of $107 \%_{0} \pm 12 \%$ between $\delta \mathrm{D}_{\text {wax }}$ and annual average precipitation (Wilkie et al., 2013). Because $n$-alkanes were not explicitly studied, and fractionation effects can be different for acids and alkanes, we choose not to apply this correction and report values as $\delta \mathrm{D}_{\text {wax }}$.

Although $\delta \mathrm{D}_{P}$ could be calculated using published global relationships, this would be misguided. Lake El'gygytgyn has a small catchment, so most alkanes will come from local Arctic plants, which may fractionate differently than most plants in the global dataset (Yang et al., 2011; Sachse et al., 2012). During the span of our 400 ka record, large biome changes have occurred, with dramatic consequences for local vegetation (Brigham-Grette et al., 2013). These shifts could have an effect on $\delta \mathrm{D}_{\text {wax }}$ that cannot be accounted for without further studies of modern plants at the lake (e.g Wilkie et al., 2013).

\section{3. brGDGTs}

As branched GDGTs have become more widely used as paleotemperature proxies, analysis of these compounds from soils in different regions of the world has revealed discrepancies in the precise relationship between the assumed temperature at production and the methylation and cyclization of the organic compounds. In response, many calibrations between instrumentally-measured temperature and the MBT and CBT indices have been proposed. Some calibrations find a more robust relationship between MAAT and the modified $\left.\mathrm{MBT}^{\prime}\right)$ index, which excludes the minor compounds IIIb and IIIc in the denominator of equation 2. Following the original study of Weijers et al. (2007b), subsequent work found major discrepancies between MBT/CBT temperature reconstructions using the original calibration and measured MAAT, particularly in lakes. To remedy 
Table 1: Linear regression between values measured with HPLC and UHPLC methods.

\begin{tabular}{lllll}
\hline \hline & BIT & MBT & CBT & T \\
\hline Slope & $1.30 \pm 0.03$ & $1.10 \pm 0.10$ & $1.06 \pm 0.07$ & $1.00 \pm 0.13$ \\
Intercept & $-0.29 \pm 0.02$ & $0.02 \pm 0.02$ & $-0.12 \pm 0.03$ & $2.25 \pm 1.26$ \\
$\mathrm{R}^{2}$ & 0.99 & 0.81 & 0.91 & 0.7
\end{tabular}

this, two lines of inquiry relevant to the present study have been explored: refinement of the global $\mathrm{MBT}\left({ }^{\prime}\right) / \mathrm{CBT}$ calibration using additional soil and lacustrine samples and improved chromatography (e.g. Peterse et al. (2012); Hopmans et al. (2016)) and development of in situ calibrations based on the relative abundances of branched GDGTs or the $\operatorname{MBT}\left({ }^{\prime}\right) / \mathrm{CBT}$ indices in lacustrine environments (e.g. Sun et al., 2011). The latter has the advantage of greatly reduced residual errors and more robust estimates of temperature change down-core. However, they require collection of soil or peat samples throughout a catchment (or region) and, ideally, sub-annually resolved sediment trap samples from the lake(s) in question. In remote regions, this can be prohibitively difficult or expensive, so a calibration must be selected from the published literature and extrapolated to the environment in question.

Barring large changes in seasonality, MAAT and MST should be highly correlated, justifying the extrapolation of calibrations based on mean annual temperature to a lake where productivity is assumed to be seasonal. However, future studies from Lake El'gygytgyn would benefit from a local calibration explicitly linking the timing and distribution of brGDGT production to measured temperatures within the lake and the catchment.

\section{Comparison between HPLC methods}

After running all of the 176 samples presented here using the HPLC method of Schouten et al. (2007), a new UHPLC method was published that results in better chromatographic separation of brGDGTs and their isomers Hopmans et al. (2016). Briefly, the new method uses two Waters UHPLC columns in series $(150 \mathrm{~mm} \times 2.1 \mathrm{~mm} \times$ $1.7 \mu$ ) and isocratically elutes GDGTs using a mixture of hexane (solvent A) and hexane:isopropanol (9:1, v:v) in the following sequene: $18 \%$ B (25 minutes), linear ramp to $35 \%$ B (25 minutes), linear ramp to $100 \%$ B (30 minutes).

To see the effect of this new method on our results, we re-ran 41 samples using the new method. The new results are shown in Fig. 2 of the main text for the BIT, MBT, and CBT indices. Table 1. Linear regression coefficients for MBT,CBT, BIT, and Temp reconstructions using the calibration of (Sun et al., 2011).

Generally, MBT values are $10 \%( \pm 10 \%)$ higher on the UHPLC method (Fig. 1a). CBT values show a more constant offset of $-0.12( \pm 0.03)$ units. This leads to consistently higher reconstructed temperatures using the Sun et al. (2011) calibration by $\sim 2 \mathrm{C}$. During MIS G3, a compound coeluting with brGDGT Ib lead to unrealistically high reconstructed temperatures. Using the UHPLC method, this compound eluted much earlier than the GDGTs, so complete separation of brGDGT Ib was acheived. During MIS G3, MBT values are lower, CBT values are higher, and temperatures are lower on the UHPLC method. This is clearly seen in the cross-plots of HPLC and UHPLC results 
(Fig. 2a,b,c). The MIS G3 data points fall on the opposite side of the 1:1 line relative to the other 37 data points. The UHPLC reconstructions demonstrate that the general shape and amplitude of the climatic changes presented here are unchanged by using the new method (Fig. 1c).

\section{Mean MIS values}

We calculated the mean value of $\delta \mathrm{D}_{\text {wax }}, \mathrm{MBT} / \mathrm{CBT}$, and pollen-based temperature for each marine isotope stage (MIS) in our record (Fig. 5). The mean for each MIS is shown as a colored box, with vertical lines indicating the standard deviation (Fig. 5). Because age model uncertainty in this part of the record is non-negligible compared to the length of many of the MIS, we also performed this analysis for the records including an age perturbation of -5 and +5 ka. For each record, and each MIS, three boxes are shown. From MIS G10 - G6, the mean values are mostly robust to age model uncertainty for all three records (Fig. 5d). From MIS G3-104, even an uncertainty of 5 ka leads to a large spread in the MIS mean values. Future work to leverage the records presented here for refining the age model will focus on these intervals. The mean values for the published age model are quoted in the text and can be calculated from the supplementary data table.

\section{Trend analysis}

The strong linear dependence of $\mathrm{MBT} / \mathrm{CBT}$ and $\delta \mathrm{D}$ on temperature in the modern environment leads to the expectation that these proxies should be coupled throughout our record. Indeed, previous paleoclimate studies have found that these proxies are coupled (e.g. Weijers et al., 2007a). As we point out in the main text, this is not what we observe. To look in more detail at the behavior of the proxies, we did two things. First, we looked at the variance in the proxy values by computing the standard deviation of each dataset in moving windows. Second, we looked at the cross correlation between the records in moving windows.

The variance analysis on $\delta \mathrm{D}_{\text {wax }}$ (Fig. $3 \mathrm{~b}$ ) shows a general trend of increasing variance throughout our record, beginning in MIS G6. The variance increases from $2 \%$ during MIS G7 to 10\% during MIS 96 when using windows of 10 data points (Fig. 3b). Each calculation is based on the same number of adjacent data points, but because the samples are unevenly spaced, this results in different window sizes for each analysis. Note that the variance of $\delta \mathrm{D}_{\text {wax }}$ increases despite the window size getting smaller. Because each analysis is based on the same number of datapoints, we expect the variance in a larger window to be larger as we are sampling a longer period of climate history. This would not be the case if we were aliasing the dominant signals in our record, but the lowest sample resolution is $4 \mathrm{kyr}$ (in the early part of the $\delta \mathrm{D}_{\text {wax }}$ record) which should be sufficient to capture the dominant frequencies of climate variability in the Pliocene Arctic. We note that for a window size of $n=10$ samples, the window length does not change dramatically through the record (Fig. refs3c). However, for this analysis, the calculated variance does share significant variation with the window size $(\mathrm{r}=-0.46, \mathrm{p}=0.004)$, suggesting that some of the increased variance we see may be an artefact of the window size getting smaller due to increased sampling resolution. 
The variance analysis on MBT/CBT also shows increasing variance beginning in MIS G6, with a large increase in variance occurring during MIS G4 (Fig. 3d). The variance during MIS G10-G7 is $\sim 0.5^{\circ} \mathrm{C}$, and increases to $2^{\circ} \mathrm{C}$ in MIS 98-96 for a window of 20 samples (Fig. 3e,f). The MBT/CBT variance record shows more structure compared with $\delta \mathrm{D}_{\text {wax }}$, with decreased variance occurring during interglacial stages MIS G5, 103, and 99. However, these features are not all robust for each of the window sizes chosen (Fig. 3e). As the sampling resolution during the earlier part of the MBT/CBT record is $3 \mathrm{kyr}$, we do not expect to be aliasing a significant portion of the real temperature variability in this record.

The cross correlation between records was calculated using the MATLAB program corrcoef which provides the coefficients of best fit from a linear regression (Fig. 3g). We calculated correlation coefficients at each time using windows of 20, 22, and 24 datapoints after interpolating the data to 2, 2.5, and $4 \mathrm{kyr}$ resolution and applying an age offset of $-5,0$, or 5 kyr to each of the records. This accomplishes two things: allows us to look at the correlations on timescales of paleoclimatic interest (shortest window $=40 \mathrm{kyr}$, longest window $=96 \mathrm{kyr}$ ) and incorporate some age offset between the two records representing potentially different residence times of the proxies. This results in 27 different correlation coefficients for each time step. We then plotted only the results with $\mathrm{p}<0.05$ (Fig. 3g). The pink shading shows the range of significant correlation coefficients found for each time-slice, and the symbols show results from the combination with a $2.5 \mathrm{kyr}$ interpolation and 22 datapoint window.

The largest positive correlation coefficients are observed from MIS 100 to MIS 97. Positive correlation coefficients are also observed from MIS G8 to MIS G3, but the range of possible correlation coefficients given the parameters we described crosses the $\mathrm{r}=0$ line during MIS G7 and G5, suggesting that the data are equivocal about the relationship between the proxies during this time. This is also the case during MIS 104. MIS 9796 shows a weak but significant negative relationship between the proxies, due to high $\delta \mathrm{D}_{\text {wax }}$ values and low reconstructed temperatures during MIS 96.

To account for the effects of serial correlation in the climatic time-series, we used the Correl MATLAB program (Macias-Fauria et al., 2012), which using a Monte Carlo approach to calculate the significance of the Pearson correlation coefficient. This approach, using 10,000 automatically generated time series with the same spectral characteristics of our records, yields the similar. For the entire time series, there is no significant correlation between the records. For MIS 100 - 98, there is a significant correlation $(r=0.764)$ above the $95 \%$ confidence interval from the Monte Carlo analysis. This is not true of any other part of the record. In fact, the other periods where our windowed correlation coefficient analysis found significant correlations (MIS G8 - G3) are not significant at the $95 \%$ confidence interval when the serial correlation of the time series is taken into account. We note that while MIS 100 - 98 is singular in our record for showing a strong coupling between $\delta \mathrm{D}_{\text {wax }}$ and MBT/CBT, this is based on only 12 samples for which both of these proxies were measured, and so should be viewed with caution until future work verifies (or refutes) this observation. 
Figure 1: Comparison of reconstructed MBT, CBT, and MBT/CBT temperature using different HPLC methods. Circles and square indicate values from the original HPLC method of Schouten et al. (2007). Filled diamonds indicate values from the UHPLC method of Hopmans et al. (2016). A) Reconstructed MBT values. B) CBT values. C) Temperature reconstruction using the calibration of (Sun et al., 2011). Orange vertical line near the y-axis shows the published calibration error $\left(4.27^{\circ} \mathrm{C}\right)$. Age control tie-points (triangles along the $\mathrm{x}$-axis) are described in the main text.

Figure 2: Cross-plots of MBT, CBT, and reconstructed temperature using different HPLC methods. Along the x-axis of each graph, values measured using the original HPLC method of Schouten et al. (2007). Along the y-axis, values measured using the UHPLC method of Hopmans et al. (2016). The dashed line in each plot is the 1:1 line, where samples would fall if there were no difference between the two methods. Samples occurring during MIS G3 are filled in and circled. A) MBT values. B) CBT values. C) ) Temperature reconstruction using the calibration of (Sun et al., 2011).

Figure 3: Trend analysis for the $\delta \mathrm{D}_{\text {wax }}$ and MBT/CBT records. A) $\delta \mathrm{D}_{\operatorname{wax}}$. B) Standard deviation of $\delta \mathrm{D}_{\text {wax }}$ in sliding windows of $n=4,6,8$ or 10 datapoints. Increasingly thick lines indicate larger windows. C) The window size for each calculated $\delta \mathrm{D}_{\text {wax }}$ standard deviation, which is a function of the number of datapoints used and the sample spacing during that interval. Lines are as in B). D) MBT/CBT temperature reconstruction using the calibration of (Sun et al., 2011). E) Standard deviation of MBT/CBT reconstruction in sliding windows of $n=8,12,16$, or 20 datapoints. Increasingly thick lines indicate larger windows. F) The window size for each calculated MBT/CBT standard deviation. G) The correlation coefficient between $\delta \mathrm{D}_{\text {wax }}$ and MBT/CBT-based temperatures. The symbols represent calculations with a window size of 22 datapoints and both time series interpolated onto $2.5 \mathrm{kyr}$ spacing. The dark green circles are for no lag, and the light green circles are for an addition of $5 \mathrm{kyr}$ to the $\delta \mathrm{D}_{\text {wax }}$ ages. The rose shading indicates the range of possible correlation coefficients for window sizes of 20,22 , or 24 samples, interpolations of $2,2.5$, or $4 \mathrm{kyr}$, and lags of $-5,0$, or $5 \mathrm{kyr}$.

Figure 4: Summary of Arctic paleoenvironmental reconstructions. MIS and age-model tie points are as in Figure 2 of the main manuscript. A) Alkenone-based SST reconstruction from ODP Site 882 (Martínez-Garcia et al., 2010). Summer Energy (Huybers, 2006) is plotted on the right-hand axis with threshold $\tau=275$. B) In pink, times reconstructed $p \mathrm{CO}_{2}$ from Martínez-Botí et al. (2015) falls below the threshold for Northern Hemisphere glaciation (in light pink, within one sigma) (DeConto et al., 2008). C) In purple, periods where southern component water bathed the North Atlantic (Lang et al., 2016). D) In brown, times of Bering Strait closure estimated from the global sea-level record of Miller et al. (2012). E) In blue, onset of sea-ice from Knies et al. (2014). F) In gray, onset of North Pacific stratification inferred by Haug et al. (2005). G) Below, pollen based biome reconstructions from Lake El'gygytgyn BrighamGrette et al. (2013) are as follows: taiga (light green), cold deciduous forest (dark green), cold steppe (blue), tundra (indigo). H) Lake El'gygytgyn $\delta \mathrm{D}_{\text {wax }}$. I) Lake El'gygytgyn MBT/CBT temperature.

Figure 5: Mean values of $\delta \mathrm{D}_{\text {wax }}, \mathrm{MBT} / \mathrm{CBT}$, and pollen temperature for each Marine Isotope Stage. A) $\delta \mathrm{D}_{\text {wax }}$. B) MBT/CBT. C) Pollen-based temperature (Brigham-Grette et al., 2013). D) Mean values for every proxy for each stage, with both temperature proxies on the right-hand axis and $\delta \mathrm{D}_{\text {wax }}$ on the left-hand axis. 
Brigham-Grette, J., Melles, M., Minyuk, P., Andreev, A., Tarasov, P., DeConto, R., Koenig, S. Nowaczyk, N., Wennrich, V., Rosen, P., Haltia, E., Cook, T., Gebhardt, C., Meyer-Jacob, C., Snyder, J., and Herzschuh, U. (2013). Pliocene Warmth, Polar Amplification, and Stepped Pleistocene Cooling Recorded in NE Arctic Russia. Science, 340:1421-1427.

Dansgaard, W. (1964). Stable isotopes in precipitation. Tellus, 16:436-468.

DeConto, R. M., Pollard, D., Wilson, P. A., Pälike, H., Lear, C. H., and Pagani, M. (2008). Thresholds for Cenozoic bipolar glaciation. Nature, 455:652-656.

Gebhardt, A. C., Francke, A., Kück, J., Sauerbrey, M., Niessen, F., Wennrich, V., and Melles, M. (2013). Petrophysical characterization of the lacustrine sediment succession drilled in Lake El'gygytgyn, Far East Russian Arctic. Climate of the Past, 9:1933-1947.

Haug, G. H., Ganopolski, A., Sigman, D. M., Rosell-Melé, A., Swann, G. E., Tiedemann, R., Jaccard, S. L., Bollmann, J., Maslin, M. A., and Leng, M. J. (2005). North Pacific seasonality and the glaciation of North America 2.7 million years ago. Nature, 433:821-825.

Hopmans, E. C., Schouten, S., and Damsté, J. S. S. (2016). The effect of improved chromatography on GDGT-based palaeoproxies. Organic Geochemistry, 93:1-6.

Huybers, P. J. (2006). Early Pleistocene Glacial Cycles and the Integrated Summer Insolation Forcing. Science, 313:508 - 511.

Knies, J., Cabedo-Sanz, P., Belt, S. T., Baranwal, S., Fietz, S., and Rosell-Melé, A. (2014). The emergence of modern sea ice cover in the Arctic Ocean. Nature Communications, 5(5608).

Lang, D. C., Bailey, I., Wilson, P. A., Chalk, T. B., Foster, G. L., and Gutjahr, M. (2016). Incursions of southern-sourced water into the deep North Atlantic during late Pliocene glacial intensification. Nature Geoscience, 9:375-379.

Macias-Fauria, M., Grinsted, A., Helama, S., and Holopainen, J. (2012). Persistence matters: Estimation of the statistical significance of paleoclimatic reconstruction statistics from autocorrelated time series. Dendrochronologia, 30(2):179 - 187. \{WORLD\} \{DENDRO\} 2010

Martínez-Botí, M. A., Foster, G. L., Chalk, T. B., Rohling, E. J., Sexton, P. F., Lunt, D. J., Pancost, R. D., Badger, M. P. S., and Schmidt, D. N. (2015). Plio-Pleistocene climate sensitivity evaluated using high-resolution $\mathrm{CO}_{2}$ records. Nature, 518:49-54.

Martínez-Garcia, A., Rosell-Melé, A., McClymont, E. L., Gersonde, R., and Haug, G. H. (2010). Subpolar link to the emergence of the modern equatorial pacific cold tongue. Science, 328:1550 1553.

Miller, K. G., Wright, J. D., Browning, J. V., Kulpecz, A., Kominz, M., Naish, T. R., Cramer, B. S., Rosenthal, Y., Peltier, W. R., and Sosdian, S. (2012). High tide of the warm Pliocene: Implications of global sea level for Antarctic deglaciation. Geology.

Nolan, M. and Brigham-Grette, J. (2006). Basic hydrology, limnology, and meteorology of modern Lake El'gygytgyn, Siberia. Journal of Paleolimnology, 37:17-35.

Pautler, B. G., Reichart, G.-J., Sanborn, P. T., Simpson, M. J., and Weijers, J. W. H. (2014). Comparison of soil derived tetraether membrane lipid distributions and plant-wax $\delta \mathrm{D}$ compositions for reconstruction of Canadian Arctic temperatures. Palaeogeography, Palaeoclimatology, Palaeoecology, 404:78-88.

Peterse, F., van der Meer, J., Schouten, S., Weijers, J. W. H., Fierer, N., Jackson, R. B., Kim, J.H., and Damsté, J. S. S. (2012). Revised calibration of the MBT-CBT paleotemperature proxy based on branched tetraether membrane lipids in surface soils. Geochimica et Cosmochimica Acta, 96:215-229.

Sachse, D., Billault, I., Bowen, G. J., Chikaraishi, Y., Dawson, T. E., Feakins, S. J., Freeman, K. H., Magill, C. R., McInerney, F. A., van der Meer, M. T. J., Polissar, P., Robins, R. J., Sachs, J. P., Schmidt, H.-L., Sessions, A. L., White, J. W. C., West, J. B., and Kahmen, A. (2012). Molecular Paleohydrology: Interpreting the Hydrogen-Isotopic Composition of Lipid Biomarkers from Photosynthesizing Organisms. Annual Review of Earth and Planetary Sciences, 40:221-249.

Schouten, S., Huguet, C., Hopmans, E. C., Kienhuis, M. V. M., and Sinninghe Damsté, J. S. (2007). Analytical Methodology for $\mathrm{TEX}_{86}$ Paleothermometry by High-Performance Liquid Chromatography/Atmospheric Pressure Chemical Ionization-Mass Spectrometry. Analytical Chemistry, 79:2940-2944.

Sun, Q., Chu, G., Liu, M., Xie, M., Li, S., Ling, Y., Wang, X., Shi, L., Jia, G., and Lü, H. (2011). Distributions and temperature dependence of branched glycerol dialkyl glycerol tetraethers in recent lacustrine sediments from China and Nepal. Journal of Geophysical Research, 116:G01008.

Wei, J. H., Finkelstein, D. B., Brigham-Grette, J., Castañeda, I. S., and Nowaczyk, N. (2014). Sediment colour reflectance spectroscopy as a proxy for wet/dry cycles at Lake El'gygytgyn, Far East 
Russia, during Marine Isotope Stages 8 to 12. Sedimentology, 61:1793-1811.

Weijers, J. W. H., Schefuß, E., Schouten, S., and Damsté, J. S. S. (2007a). Coupled thermal and hydrological evolution of tropical africa over the last deglaciation. Science, 315(5819):1701-1704.

Weijers, J. W. H., Schouten, S., van den Donker, J. C., Hopmans, E. C., and Sinninghe Damsté, J. S. (2007b). Environmental controls on bacterial tetraether membrane lipid distribution in soils. Geochimica et Cosmochimica Acta, 71:703-713.

Wilkie, K. M. K., Chapligin, B., Meyer, H., Burns, S., Petsch, S., and Brigham-Grette, J. (2013). Modern isotope hydrology and controls on $\delta \mathrm{D}$ of plant leaf waxes at Lake El'gygytgyn, NE Russia. Climate of the Past, 9:335-352.

Yang, H., Liu, W., Leng, Q., Hren, M. T., and Pagani, M. (2011). Variation in n-alkane dD values from terrestrial plants at high latitude: Implications for paleoclimate reconstruction. Organic Geochemistry, 42:283-288. 